\title{
Economic Scheduling of the Electric Transmission/ Distribution Substations in Jeddah City with Parametric Results
}

\author{
Said Ali El-Quliti and Mohammed Reda Kabli \\ Department of Industrial Engineering, King Abdulaziz University, \\ Jeddah, Saudi Arabia
}

\begin{abstract}
This paper is devoted to economically scheduling the number of electric transmission/ distribution substations for long-term time horizon $(2011-2020)$. The schedule aims at minimizing the total costs while maintaining the problem constraints based on a dynamic programming model.
\end{abstract}

There are many parameters affecting the solution of the problem, these parameters are: initial value of the substation building cost, percentage of yearly increase in the substation building cost, percentage of discount for buying more than one substation, and present and future values of the operation cost.

The proposed dynamic programming model will provide Saudi Electricity Company (SEC) with a systematic procedure to arrive at the best decision based on the optimal combination of the number of substations to be built in each year during the planning time horizon. It gives also an overview for the sensitivity range of parameter changes for the same optimal solution, and gives other optimal solution ranges for more changes in the parameters.

Keywords: Scheduling, Parametric Results, Dynamic Programming, Electric Transmission/ Distribution Substations.

\section{Introduction}

The major concern of Saudi Electricity Company (SEC) is to provide adequate supply of electricity to the public and industry in each area in Jeddah city. Because the power demand is going to exceed the electricity 
endurance in a direct proportion to the definite growth in population, the building environment expansion, extensively SEC will be required to reinforce the network by the installation of new substations in these areas.

The procedure that SEC follows now depends fully on immediate actual needs in the current year for each area in the city taking into account the budget constraints. This may result on the one hand to building few substations in some years while the budget permits for more, and on the other hand in building less than required in other years because of the budget constraints. To avoid such results and to achieve economic decisions, SEC is in bad need to build a systematic procedure for determining the optimal combination of decisions to determine the number of substations to be built in each year during the overall planning time horizon. This is a very important and vital issue for (SEC), it will help to avoid decision problems by building a mathematical model for optimal scheduling under the constraints of needed demand and budget availability.

El Quliti et al. (2009) ${ }^{[1]}$ focused their work on the electricity field in Jeddah city; their paper is devoted to economically scheduling the needed number of electric transmission/distribution substations for longterm time horizon from 2006 to 2015. The forecasting of needed number of substations is based on predicting the electricity total consumption in each year and then finding the number of substations needed for each year.

Al Ghamdi (2010) ${ }^{[2]}$ continued the previous work, he focused also on the electricity field in Jeddah city, but the schedule is done for the time horizon from 2011 to 2020 . He expands the work to contain some parametric results studying the effect of change of the problem parameters on the obtained optimal solution.

This paper is derived from the work of Al Ghamdi (2010) ${ }^{[2]}$, it is devoted to economically scheduling the needed number of electric transmission/distribution substations for a long-term time horizon (from 2011 to 2020). The scheduling aims at minimizing the total costs based on a dynamic programming model. The proposed dynamic programming model will provide SEC with a systematic procedure to arrive at the best decision based on the optimal combination of the number of substations to be built in each year during the planning time horizon. It gives also an 
overview for the sensitivity range of parameter changes for the same optimal solution, and gives other optimal solution ranges for more changes in the parameters.

The paper also gives many parametric results showing the effect of various changes in the problem main parameters on the optimal solution, these parameters are: initial value of the substation building costs, percentage of yearly increase in the substation building costs, percentage of discount for buying more than one substation, and present and future values of the operation costs.

\section{Literature Review}

Expert opinions indicate that one of the major information required in planning for future capacity resource needs is the forecasted load demand. The Ministry of Planning in the Kingdom of Saudi Arabia, (2009) ${ }^{[3]}$ in its plan for $2010-2014$, states that the population forecast in Jeddah city is expected to be increased within the next 25 years with an increasing rate of $2.2 \%$ a year. This increase in population should be accompanied by an appropriate increase in electricity supply to meet the expected increase in demand. A long-term forecast is commonly known as an annual peak load of energy forecast. This type of forecast is important in deciding on the system generation and transmission expansion plans used in this paper.

Gelling C.W et al. (1992) ${ }^{[4]}$ divided electric demand forecasting into three categories, namely, short-term, medium-term and long-term depending on the time horizon under consideration. Short-term forecasting is intended for few hours and is important in the day-to-day operations of utilities such as unit commitment, economic dispatch, load management, ...etc. Medium-term forecasting is valid for a few weeks to a few months and even up to a few years. It is necessary in planning fuel procurement, scheduling unit maintenance etc. Long-term forecasting is valid for 5 to 15 years and up to 25 years. Unlike short-term load forecasting, long-term load forecasting is mainly affected by economic factors rather than weather conditions.

Several studies for load forecasting exist in the literature, for example, Parols et al. (1995) ${ }^{[5]}$ found that an essential element of electric utility resource planning is forecasting of the future load demand in the 
service area. Based on the outcome of such forecasts, utilities coordinate their resources to meet the forecasted demand using a least-cost plan.

Nagasaka and Al Mamun (2004) ${ }^{[6]}$ discussed the prediction of peak loads in Japan up to the year 2010 using the radial basis function networks (RBFNs). In their study, total system load forecast reflecting the current and future trends is carried out for 9 power companies in Japan. Predictions were done for target years 2001 to 2010. The study focuses on economical data that seem to have influence on long-term electric load demand. The data used here are only: actual yearly load, incremental growth rate from previous years, and blend (actual and incremental growth rate from previous years).

Different methods are used for planning purposes; some of which are suitable only for short term plans. Ganjavi (2001) ${ }^{[7]}$ proposes a method for primary and secondary distribution system planning in a coordinated hierarchy. The required data are supplied by a geographical data system, and the problem is solved by a load-modeling program. This may be suitable for short term planning, but it is inappropriate for a longterm one.

Dynamic programming approach is used as a method for scheduling in many areas of application. Few researches touch the distribution substations. For example, Lu and Hsu (1995) ${ }^{[8]}$ investigated an approach based on dynamic programming to reach the dispatching schedule for the control of reactive power/voltage in a distribution substation. To demonstrate the usefulness of the proposed approach, reactive power/voltage control in a distribution substation within the service area of Taipei City District Office of Taiwan Power Company is performed.

Pseudo-dynamic technique is used by Yn et al. (2000) ${ }^{[9]}$ to solve the problem of optimal planning of substation locations and sizes. The spatial load forecast is used to forecast the distribution load demand in the planning area in future years. The planning area is divided into lots of small sectors (areas). A forecast approach based on classification of the small sectors is selected. They use a pseudo-dynamic technique to solve the problem in two steps, first find out the optimal substation locations and sizes at target year, second separate the whole planning period (from current year to target year) into several stages with several interior years. Then find out the optimal planning of substation locations and sizes at 
each stage which minimizes the investment and operation costs in total during this stage.

\section{Data Collection}

It is needed to make long-term forecasting for electricity consumption depending on the past data of electricity consumption and on the factors affecting this consumption. Al-Ghamdy $(2010)^{[2]}$ collected the needed data for annual total electricity consumption in Jeddah city for the period 1979-2010 from official annual reports of the Saudi Electricity Company (2010) ${ }^{[10]}$.

There is a number of economic and demographic variables that could have a considerable impact on the electricity consumption. Depending on the effect of these variables, they would lead towards the increase or decrease of the total electricity consumption. The experts and researchers from the SEC Company are consulted to determine the economic and demographic variables that affect the electricity consumption. Al-Ghamdi (2010) ${ }^{[2]}$ collected values of these variables for the same planning period from the Chamber of Commerce and Industry in Jeddah (2010) ${ }^{[11]}$; he used these economic and demographic factors as inputs variables to the Neural Network to forecast the future electric consumption. The used factors are: Oil Gross Domestic Product, Private Non-Oil Gross Domestic Product, Government Non-Oil, Gross Domestic Product, Per Capita Income, Population Size, and Total Number of Subscribers.

The number of required substations to be built in Jeddah city during the coming ten years (from 2011 to 2020) is calculated depending on result of forecasting annual total consumption. The electrical total consumption (recorded energy) in Jeddah city is converted to recorded demand load. The forecasting is done using two methods; Multiple Regression Analysis explained in Hanke et al. (2008) ${ }^{[12]}$, and Artificial Neural Networks software done by Neuro Dimension Inc. $(2008)^{[13]}$. The forecasting results of the Neural Network with an error ranging up to $2.11 \%$ only (calculated by the used software) were more accurate than that of the regression method. The errors are determined by using the common methods for calculating the forecasting errors in literature, for example Hanke et al. (2008) ${ }^{[12]}$, Evans (2005) ${ }^{[14]}$, and Carnot et al. $(2005)^{[15]}$. 
The model used for the neural network is the Multilayer perceptrons (MLPs) model. There are seven basic steps of neural networks for this model:

Step 1: Input/desired data file selection

Step 2: Cross Validation and Test Data

Step 3: Neural Topology

Step 4: Layer configuration

Step 5: Simulation control

Step 6: Data Display (Probe Configuration)

Step 7: Simulation

The details of these steps are fully explained in a complete chapter in the thesis of Al-Ghamdi $(2010)^{[2]}$.

The forecasting results reveal that the required numbers of substations for the coming 10 years are as follows: $(3,1,3,3,3,3,0,3$, 3 , and 3) respectively.

\section{The Dynamic Programming Model}

Dynamic programming is a very useful mathematical technique for making a sequence of interrelation decisions. It provides a systematic procedure for determining the optimal combination of decisions.

Hillier (2005) ${ }^{[16]}$ states that there is no standard mathematical formulation of the dynamic programming problem. Rather, dynamic programming is a general type of approach to problem solving, and the particular equations used must be developed to fit each situation. Therefore, a certain degree of ingenuity and insight into the general structure of dynamic programming problems is required to recognize when and how a problem can be solved by dynamic programming procedures. These abilities can best be developed by an exposure to a wide variety of dynamic programming applications and a study of the characteristics that are common to all these situations.

\subsection{Recursive Relationship}

El Quliti et al. (2009) ${ }^{[1]}$ produced a recursive relationship that identifies the optimal policy for stage $n$, given the optimal policy for stage $n+1$, is available. The precise form of the recursive relationship differs somewhat among dynamic programming problems. The notations 
used in formulating dynamic programming problems are summarized below.

$$
\begin{aligned}
& N=\text { number of stages. } \\
& n=\text { label for current stage }(n=1,2, \ldots, N) . \\
& s_{n}=\text { current state for stage } n . \\
& x_{n}=\text { decision variable for stage } n . \\
& \left.x_{n}^{*}=\text { optimal value of } x_{n} \text { (given } s_{n}\right) .
\end{aligned}
$$

$f_{n}\left(s_{n}, x_{n}\right)=$ contribution of stages $\mathrm{n}, \mathrm{n}+1, \ldots, N$ to objective function if system starts in state $s_{n}$ at stage $n$, immediate decision is $x_{n}$, and optimal decisions are made therefore.

$$
f_{n}^{*}\left(s_{n}\right)=f_{n}\left(s_{n}, x_{n}^{*}\right) .
$$

The recursive relationship will always be in the form

$$
f_{n}^{*}\left(s_{n}\right)=\max _{x_{n}}\left\{f_{n}\left(s_{n}, x_{n}\right)\right\} \quad \text { or } \quad f_{n}^{*}\left(s_{n}\right)=\min _{x_{n}}\left\{f_{n}\left(s_{n}, x_{n}\right)\right\}
$$

\subsection{Optimal Solution}

When using this recursive relationship, the solution procedure starts at the end and moves backward stage by stage each time finding the optimal policy for the stage until it finds the optimal policy starting at the initial stage. This optimal policy immediately yields an optimal solution for the entire problem, namely, $x_{1}^{*}$ for the initial state $S_{1}$, then $x_{2}^{*}$ for the resulting state $s_{2}$, and so on to $x_{N}^{*}$ for the resulting stage $S_{N}$.

\subsection{Backward Solution Procedure}

The backward solution requires making ten interrelation decisions, namely, how many number of electric transmission/distribution substations to build in each year of the coming ten years. These ten years can be considered as the ten stages in a dynamic programming formulation.

$>$ The decision variables $x_{n}(n=1,2,3,4,5,6,7,8,9,10)$ are the number of substations to be built in stage (year) $n, n=1,2, \ldots, 10$.

$>$ The appropriate choice for the "state of the system" is $S_{n}=$ number of substations still required in remaining years. 


\subsection{States of the System}

The states for the network can be calculated as follows: At stage 1 (year 1), where nothing of the required substations is built, $S_{1}=$ summation of the total number of required substations in all stages $\left(D_{N}=25\right)$. At the second stage (year 2), $S_{2}$ is just $D_{N}$ minus the number of substations built at the preceding stages, and so on:

$$
S_{n}=S_{n-1}-x_{n-1}, n=2,3, \ldots . ., 10 .
$$

So the sequence of states is:

$$
\begin{aligned}
& \text { 1. } S_{1}=D_{N} \\
& \text { 2. } S_{2}=D_{N}-x_{1} \\
& \text { 3. } S_{3}=S_{2}-x_{2} \\
& \text { 10. } S_{10}=S_{9}-x_{9}
\end{aligned}
$$

With the dynamic programming procedure of solving backward stage by stage, when we are solving at stage 2 we shall not yet have solved for the building at preceding stage. Therefore, we shall consider every possible state we could be in at stage 2 , namely $S_{n}=0,1,2, \ldots ., 24$ or 25 .

\subsection{Data for the Problem Constraints}

AL-Ghamdi (2010) ${ }^{[2]}$ collected the relevant data for the problem, the electricity consumption in each year is obtained from the official documents of the company, the upcoming consumption is forecasted using Artificial Neural Networks, and the problem parameters (building cost, discount if the number of substations is more than one, yearly increase in building cost, operation and maintenance costs and their yearly increase) are consulted by the experienced and responsible persons in the company. Table 1 contains the data for the problem constraints. Building cost is assumed to start from 50 million Saudi Riyals (SR) at year 2011 for one substation and there is a discount if the number of substations is more than one by $(0.05 *$ number of substations added). Also, building cost is assumed to increase yearly by an average of $7 \%$ from the previous year. Operation and maintenance costs start from three millions SR in the first year and increase yearly by $7 \%$ from the previous year. 
Table 1. Data for problem constraints.

\begin{tabular}{|c|c|c|c|c|c|c|c|c|c|c|}
\hline \multirow{2}{*}{$\begin{array}{c}\text { \# of } \\
\text { Substations }\end{array}$} & \multicolumn{10}{|c|}{ Year (Stage) } \\
\cline { 2 - 12 } & $\mathbf{1}$ & $\mathbf{2}$ & $\mathbf{3}$ & $\mathbf{4}$ & $\mathbf{5}$ & $\mathbf{6}$ & $\mathbf{7}$ & $\mathbf{8}$ & $\mathbf{9}$ & $\mathbf{1 0}$ \\
\hline 0 & 0 & 0 & 0 & 0 & 0 & 0 & 0 & 0 & 0 & 0 \\
\hline 1 & 50.00 & 53.50 & 57.25 & 61.25 & 65.54 & 70.13 & 75.04 & 80.29 & 85.91 & 91.92 \\
\hline 2 & 95.00 & 101.65 & 108.77 & 116.38 & 124.53 & 133.24 & 142.57 & 152.55 & 163.23 & 174.65 \\
\hline 3 & 135.00 & 144.45 & 154.56 & 1665.38 & 176.96 & 189.34 & 202.60 & 216.78 & 231.96 & 248.19 \\
\hline Budget & 150 & 161 & 172 & 184 & 197 & 210 & 225 & 241 & 258 & 276 \\
\hline $\mathrm{D}_{\mathrm{n}}$ & 3 & 4 & 7 & 10 & 12 & 14 & 16 & 19 & 22 & 25 \\
\hline Op. cost & 3.00 & 3.21 & 3.43 & 3.68 & 3.93 & 4.21 & 4.50 & 4.82 & 5.15 & 5.52 \\
\hline
\end{tabular}

\subsection{The Objective Function}

To state the overall problem mathematically, let the cost to building $x_{n}$ substations in year $n$, and cost of operation and maintenance for these substations are as given in Table 1. Thus, the objective is to choose $x_{1}, x_{2}, x_{3}, \ldots \ldots ., x_{10}$ so as to:

Minimize $\sum_{n=1}^{10} p_{n}\left(x_{n}\right)+\left(x_{n}^{*} \sum_{i=n+1}^{10} o_{i}\right)$

Where:

$$
\begin{array}{ll}
p_{n}\left(x_{n}\right) & =\text { Building Cost for } x_{n} \text { substations } \\
o_{i} & =\text { Total Operations Cost for } x_{n} \text { substations }
\end{array}
$$

Subjected to:

\subsection{Problem Constraints}

- Total Number of Substations:

$$
\sum_{n=1}^{10} x_{n}=D_{N}=25
$$

- Budget Constraints:

$$
x_{n} \leq 3, \mathrm{n}=1,2, \ldots \ldots ., 10
$$

- Number of required substations Constraints:

$x_{1} \geq 3 \quad$ (Number of required substations in first year)

$x_{1}+x_{2} \geq 4$ (Number of required substations in second year) 


$$
\begin{aligned}
& x_{1}+x_{2}+x_{3} \geq 7 \\
& x_{1}+x_{2}+x_{3}+x_{4} \geq 10 \\
& x_{1}+x_{2}+x_{3}+x_{4}+x_{5} \geq 12 \\
& x_{1}+x_{2}+x_{3}+x_{4}+x_{5}+x_{6} \geq 14 \\
& x_{1}+x_{2}+x_{3}+x_{4}+x_{5}+x_{6}+x_{7} \geq 16 \\
& x_{1}+x_{2}+x_{3}+x_{4}+x_{5}+x_{6}+x_{7}+x_{8} \geq 19 \\
& x_{1}+x_{2}+x_{3}+x_{4}+x_{5}+x_{6}+x_{7}+x_{8}+x_{9} \geq 22 \\
& x_{1}+x_{2}+x_{3}+x_{4}+x_{5}+x_{6}+x_{7}+x_{8}+x_{9}+x_{10} \geq 25
\end{aligned}
$$

- Non-negativity and integrality Constraints: $x_{n}, \mathrm{n}=1,2, \ldots, 10$ are nonnegative integers.

\section{Graphical Representation and Solution}

Figure 1 shows the states to be considered at each stage. The links (line segments) show the possible transitions in states from one stage to the next by building a feasible of substations in the year involved. Starting from stage 1 (first year), where the initial state equal 25 that means the number of substations still required to be built is 25 substations, and according to the constraints mentioned that during the first year it must be build at least three substations $\left(x_{1} \geq 3\right)$. And also, budget constraint does not allow to build more than three substations ( $\left.x_{1} \leq 3\right)$ in the first year. This means that there are only one choice, that is to build three substations and thus bringing the number of substations remaining 22 (state $=22$ ) as shown in second column in the figure, and so on for the other stages. The overall problem is to find the path from the initial state 25 (beginning stage 1 ) to the final state 0 (after stage 10) that minimizes the sum of the total cost along the path.

A special program was developed using (VBA) language under Microsoft Office Excel software to build a dynamic programming procedure for solving the problem of this research. Many references give 
the fundamentals of VBA, see for example Walkenbach (2007) ${ }^{[17]}$ and Jelen $(2008)^{[18]}$. The program allows the user to change the values of main inputs data for the problem that is cost of building substations and the annual budget and the annual operating cost which logically may require a user to change based on the available data.

The results of dynamic programming model are summarized in Figure 2. The obtained optimal solution is to build the following number of substations: $(3,1,3,3,3,3,0,3,3$, and 3$)$ respectively in the coming 10 years $(2010-2020)$ with total cost of SR 2,083,220,000.

\section{Analysis of Results}

The experts and decision makers of SEC are consulted to analyze the stated problem and give their comments on the obtained optimal solution. They agreed that the procedure followed by SEC now depends fully on immediate actual needs in the current year taking into account the budget constraints.

They agreed about the validity of the forecasting results, and propose as a solution for the planning problem to build $(3,1,3,3,3,3,0$, $3,3$, and 3$)$ respectively in the coming 10 years $(2010-2020)$ to fill the immediate demand for the electricity consumption.

Considering the same values for the problem parameters, this proposed solution will comprise a total cost of SR 2,472,783,000 which is higher than the obtained optimal solution of SR 2,083,220,000 with SR $389,563,000$.

The obtained optimal solution depends on the initial values for the problem parameters. The values for these parameters are consulted with experienced and responsible persons from the STC. They provide the current market values as:

- Initial value of a substation building cost is 50 million riyals per substation.

- The percentage of yearly increase in the building cost is $7 \%$.

- The percentage of discount for buying more than one substation is $5 \%$. 
- Initial value of the operation cost is 3 million riyals per substation.

- The percentage of yearly increase in the operation cost is $7 \%$.

These values are subject to market fluctuations and can change in the coming years, and for this reason, it is necessary to study the effect of these potential changes on the optimal solution of the problem.

\section{Parametric Results}

\subsection{The Same Optimal Solution}

Since the problem parameters are subject to fluctuations, it is necessary to determine the range of values for these parameters that give the same optimal solution $(3,1,3,3,3,3,0,3,3$, and 3$)$ respectively, they are:

i) Initial value of the substation building cost between $(19.4-51.5)$ million Saudi Riyals per substation. Figure 3 shows the relation of the Total Optimum Value (TOV) with different initial substation building cost.

ii) The percentage of yearly increase in substation building cost between $(0 \%-7 \%)$, Fig. 4.

iii) The percentage of discount for buying more than one substation (5\% or more), Fig. 5.

iv) Initial value of the operation cost between $(2.95-7.7)$ million riyals per substation, Fig. 6 .

v) The percentage of yearly increase in operation cost between (6 $25 \%)$ Fig. 7.

\subsection{Changes in the Optimal Solution}

If changes in parameters are outside these ranges, another optimal solution appears; we can then obtain the new optimal solution by changing the parameters and resolve the dynamic programming model once again: 


\subsubsection{Optimal Solution (3, 1, 3, 3, 2, 2, 2, 3, 3, and 3)}

Another optimal solution (3, 1, 3, 3, 2, 2, 2, 3, 3, and 3) is obtained for the following values of the problem parameters:

i) Initial value of the substation building cost is reduced to any value less than 19.3 million Saudi Riyals per substation, Fig. 8.

ii) Percentage of discount for buying more than one substation is cancelled.

iii) Initial value of the operation cost is increased more than 7.8 million Saudi Riyals per substation.

iv) Percentage of yearly increase in operation cost is increased more than $30 \%$.

\subsubsection{Optimal Solution (3, 1, 3, 3, 3, 3, 3, 3, 3, and 0)}

Another optimal solution (3, 1, 3, 3, 3, 3, 3, 3, 3, and 0) is obtained for the following values of the problem parameters:

i) Initial value of the substation building cost between $(51-53.9)$ million Saudi Riyals per substation.

ii) If the initial value of the operation cost is changed to any value between $(2.79-2.94)$ million Saudi Riyals per substation.

iii) If the percentage of discount for buying more than one substation is changed to any value between $(3 \%-4 \%)$.

\subsubsection{Optimal Solution (3, 3, 3, 3, 3, 3, 3, 3, 1, and 0)}

Another optimal solution (3, 3, 3, 3, 3, 3, 3, 3, 1, and 0$)$ is obtained for the following values of the problem parameters:

i) Initial value of the substation building cost is increased to any value more than 54 million Saudi Riyals per substation.

ii) Percentage of discount for buying more than one substation is changed between $(1 \%-2 \%)$.

iii) Percentage of yearly increase in the building cost is increased more than $8 \%$. 
iv) Initial value of the operation cost is decreased to any value less than 2.78 million Saudi Riyals per substation.

v) Percentage of yearly increase in operation cost is changed for any value between $(0 \%-5 \%)$.

\subsection{Analysis of the Effects of Changes in Problem Parameters}

By thorough examination of the last points, these results are observed:

1. The dynamic programming study gives the optimal solution $(3,1,3,3,3,3,0,3,3,3)$ under the constraint's parameters. The same optimal solution with range of changes in each parameter.

2. If a parameter changes outside that range; another optimal solution is created. This gives the decision maker a chance to select the best solution for any changes that may happen in the future.

3. Usually there are linear trend between the total optimum value and the parameter changes.

4. The optimal solutions give a strategy to build fewer substations in early years of the plan for the following conditions:

- If the initial value of the substation building cost has been reduced to less than 19.3 million riyals per substation.

- If the initial value of the operation cost has been increased to more than 7.8 million riyals per substation.

5. The optimal solutions give a strategy to build more substations in early years of the plan for the following conditions:

- If the initial value of the substation building cost has been increased to more than 55 million riyals per substation.

- If the initial value of the operation cost has been decreased to less than 2.72 million riyals per substation. 


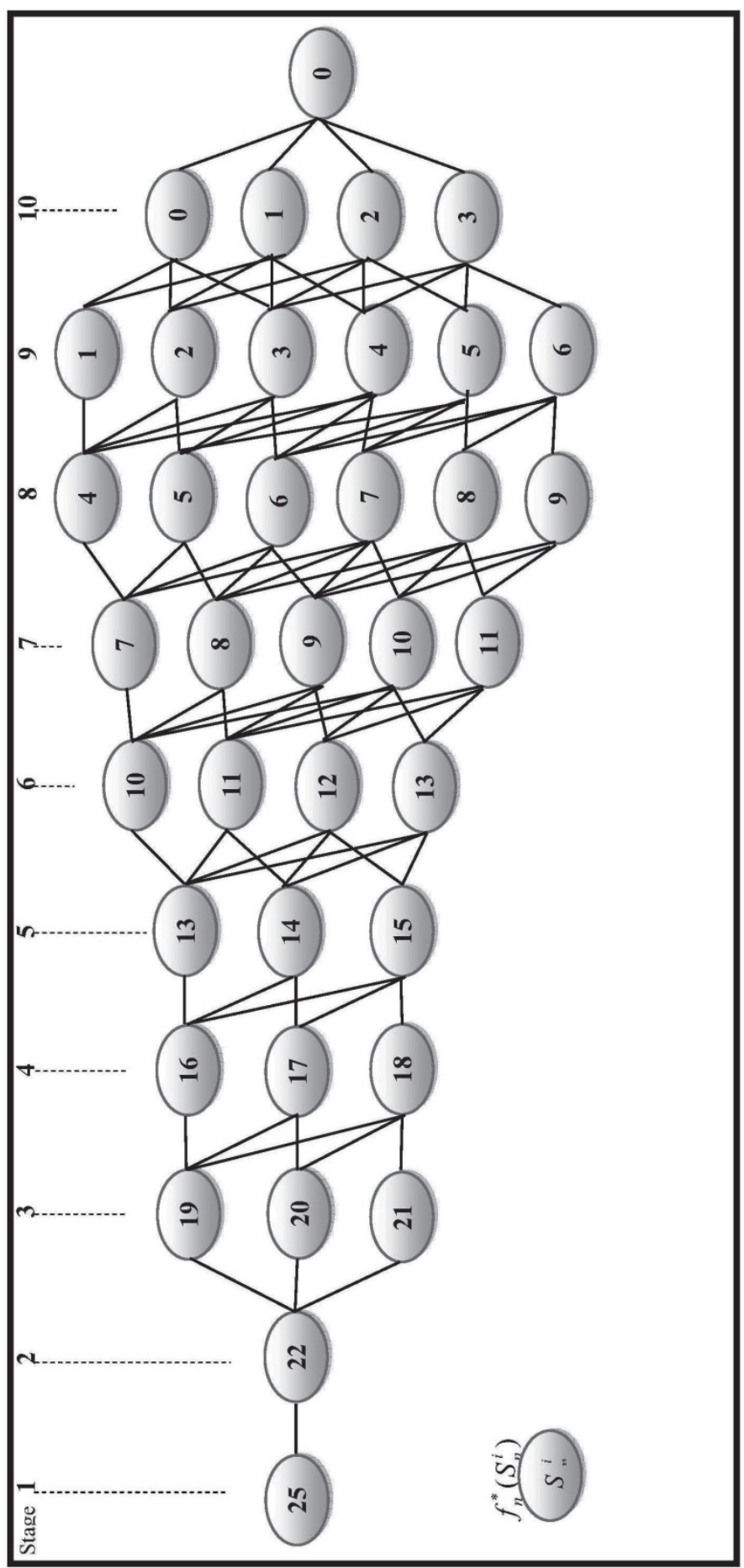

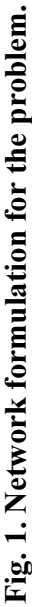




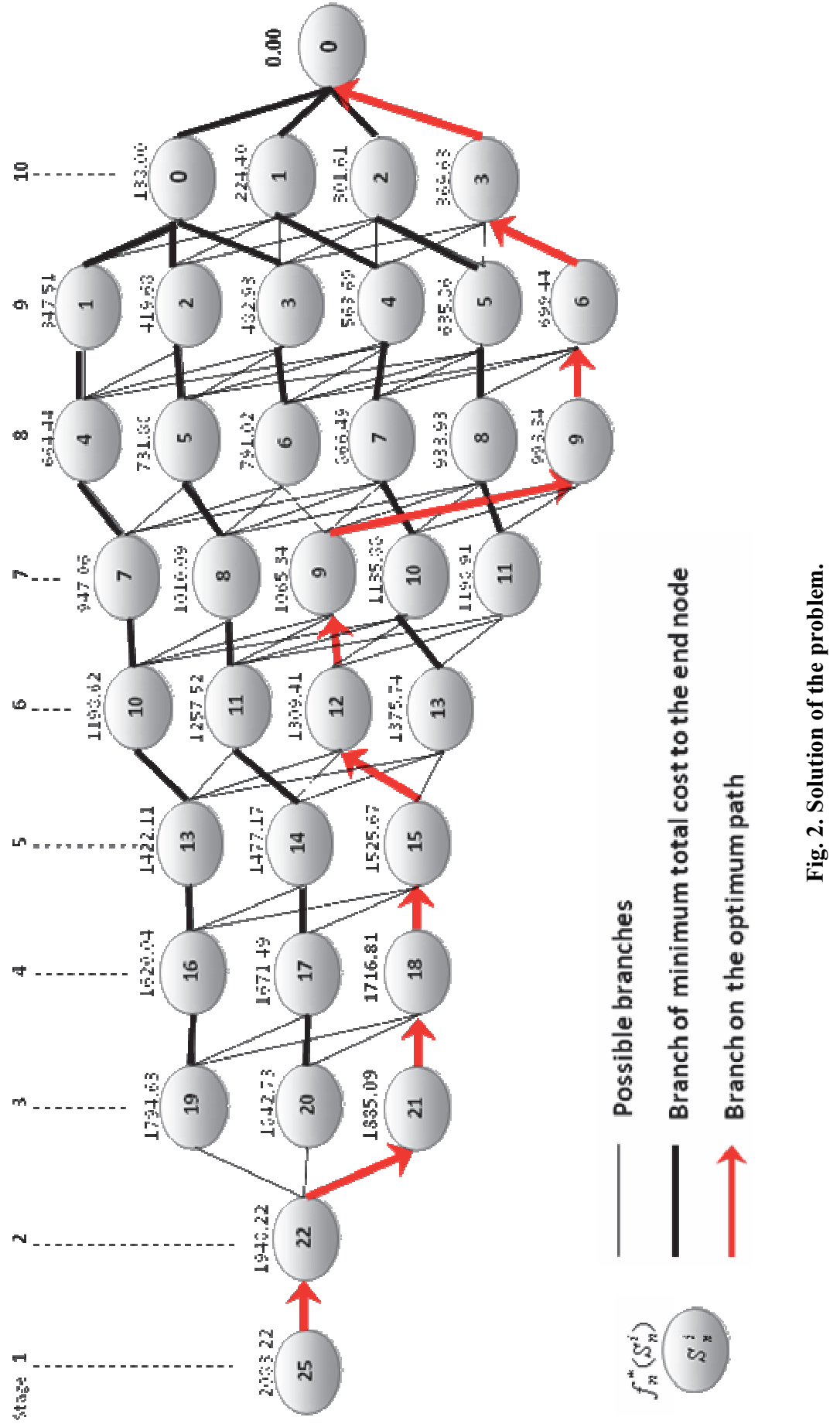




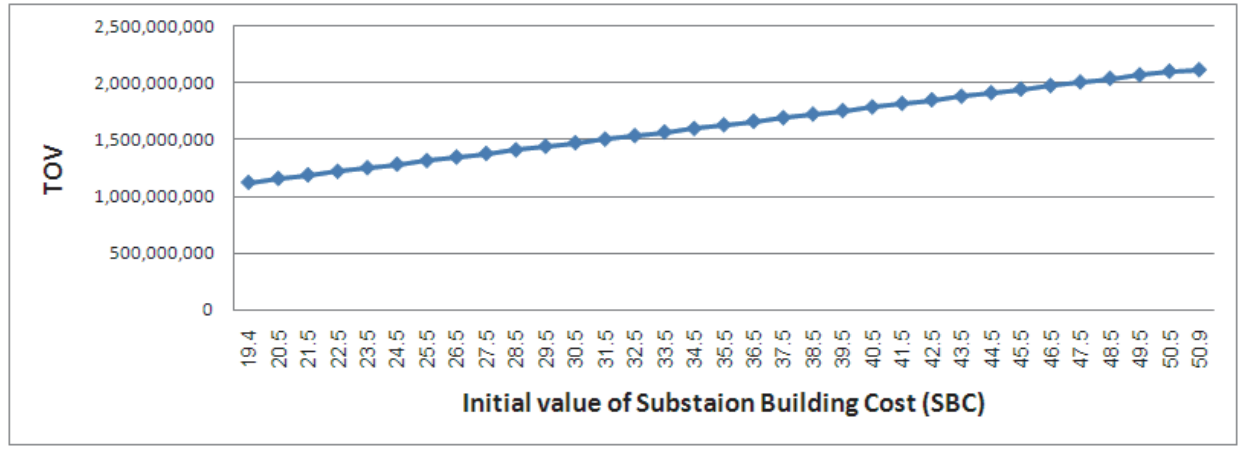

Fig. 3. Total Optimum Values for different initial building cost.

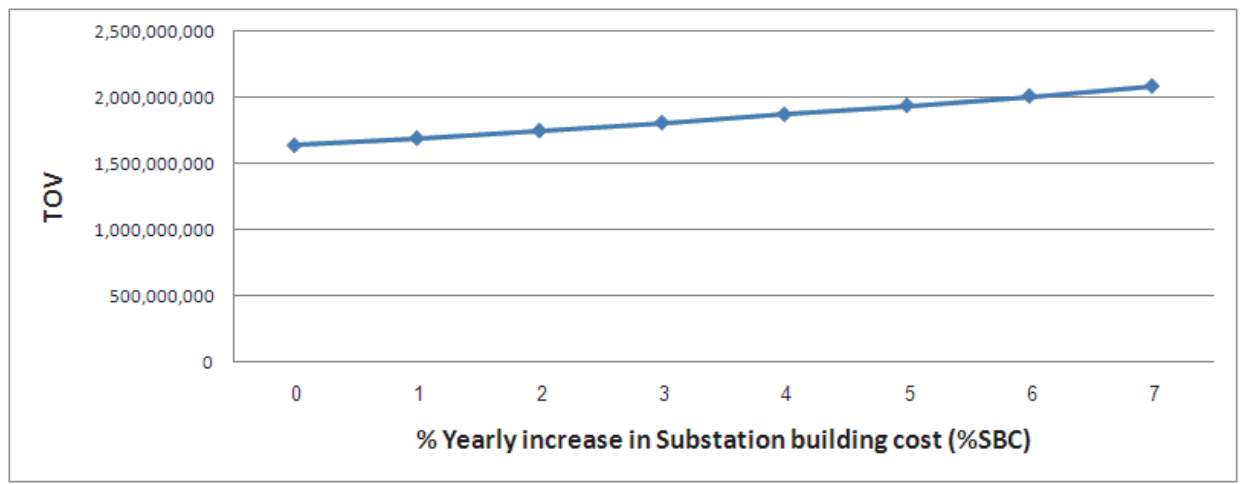

Fig. 4. (TOV) for different increases in building cost.

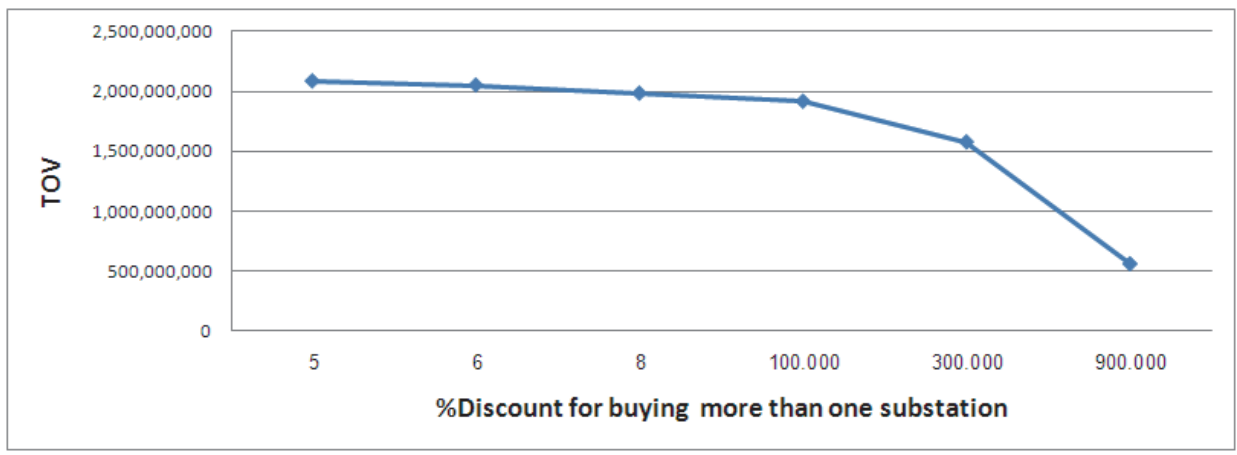

Fig. 5. (TOV) for different discounts for substation's cost. 


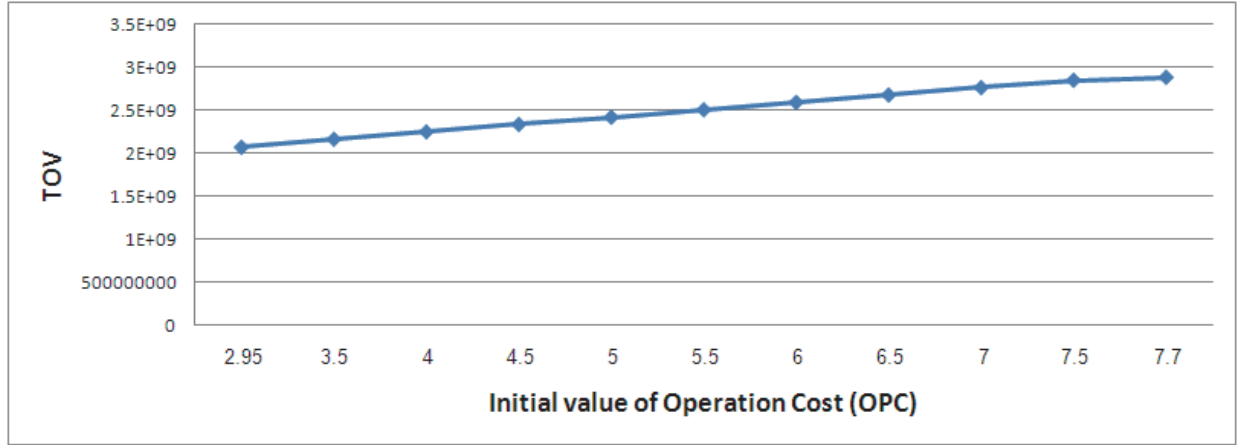

Fig. 6. (TOV) for different initial operation cost.

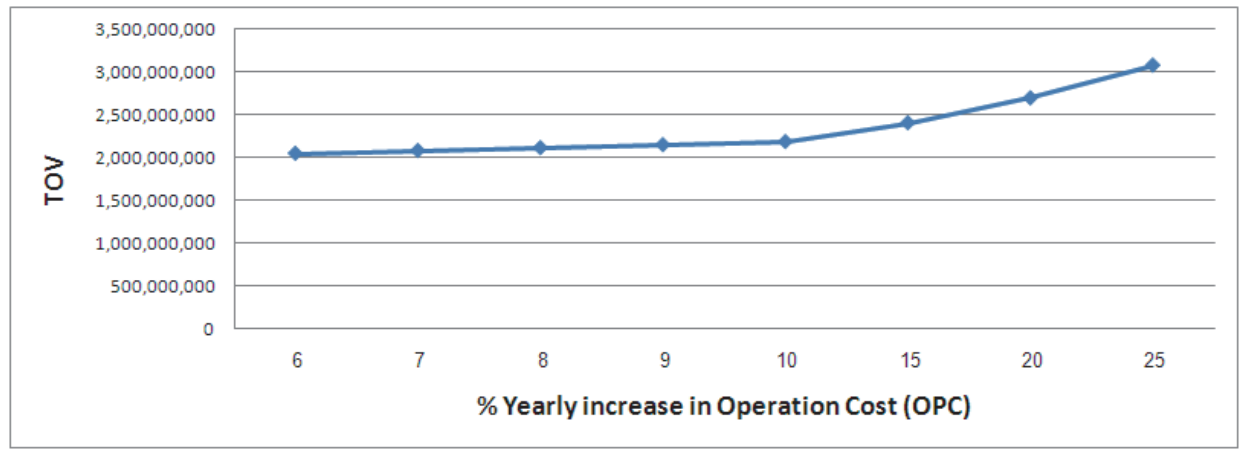

Fig. 7. (TOV) for different \% yearly increase in operation cost.

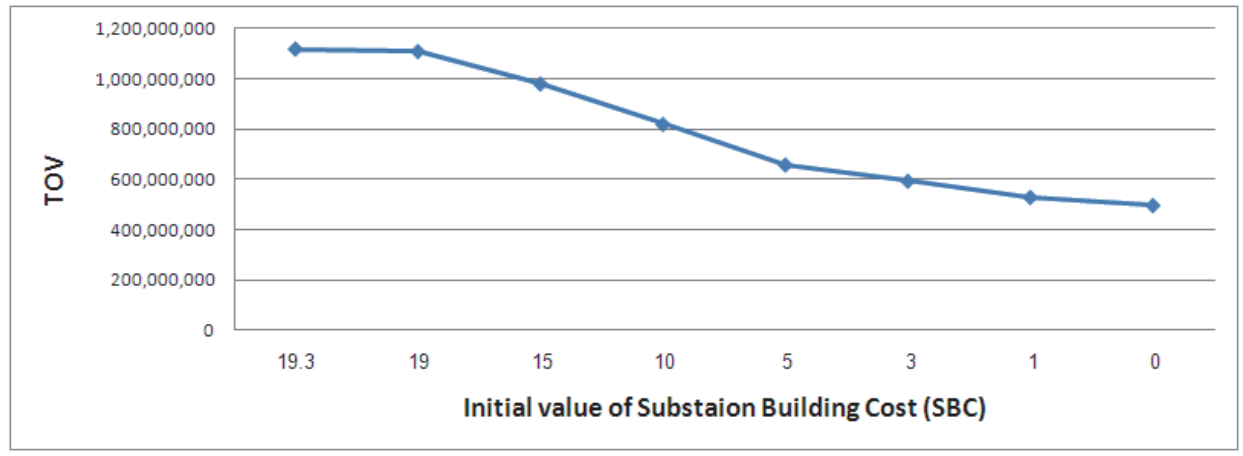

Fig. 8. (TOV) for different substation building cost. 


\section{Conclusions}

1. A backward model of dynamic programming approaches is used. It is formulated to determine the optimum number of substations to be built in each year during the planning time horizon.

2. The obtained optimal solution is to build the following number of substations: $(3,1,3,3,3,3,0,3,3$, and 3$)$ respectively in the coming 10 years $(2010-2020)$ with total cost of SR 2,083,220,000.

3. Considering the same values for the problem parameters, the proposed solution given by the decision makers of SEC will comprise a total cost of SR 2,472,783,000 which is about $18.7 \%$ higher than the obtained optimal solution for the given problem.

4. The parameters affecting the optimal solution of the problem are:

- The initial value of the substation building cost.

- The percentage of yearly increase in the substation building cost.

- The percentage of discount for buying more than one substation.

- The initial value of the operation cost.

- The percentage of yearly increase in the operation cost.

5. The optimal solutions give a strategy to build fewer substations in early years of the plan for the following conditions:

- If the initial value of the substation building cost has been reduced to less than 19.3 million riyals per substation.

- If the initial value of the operation cost has been increased to more than 7.8 million riyals per substation.

6. The optimal solutions give a strategy to build more substations in early years of the plan for the following conditions:

- If the initial value of the substation building cost has been increased to more than 55 million riyals per substation.

- If the initial value of the operation cost has been decreased to less than 2.72 million riyals per substation. 


\section{Points for Future Researches}

1. To prove analytically the obtained parametric study results and to analyze and the sudden changes in the optimal values in relation to the changing parameters. horizon.

2. To study in detail the time value of money over the planning

3. To build a decision support system and to use it for other regions of the Kingdom of Saudi Arabia.

\section{References}

[1] El Quliti, S.A., El-Darrab, I.A. and Al-Ameer, M.A. (2009). A Dynamic Programming Model for Scheduling the Electric Transmission/Distribution Substations in Jeddah City, WSEAS Intern. Conferences, Univ. of Cambridge, Cambridge, United Kingdom.

[2] Al-Ghamdi, S.S. (2010). A Dynamic Programming Model with Parametric Study for Scheduling the Construction of Electric Transmission/ Distribution Substations in Jeddah City. M. Sc. Dissertation, Deptment of Industrial Engineering, Faculty of Engineering, King Abdulaziz university, Jeddah.

[3] Ministry of Planning (2009). Ninth Development Plan 2010 - 2014, Kingdom of Saudi Arabia.

[4] Gelling, C.W., Barron, W.L., Chamberlain, J.H., Faruqui, A. and Smith, B.A. (1992). Demand Forecasting for Electric Utilities. Fairmont Press Inc., Libborn, USA.

[5] Parols, A.G., Esmaeil, O., Muthusami, J., Patton, A. and Atiya, A.F. (1996). Development of an Intelligent Long-Term Electric Load Forecasting System, Intelligent Systems Applications to Power Systems, Proceeding, ISAP International Conference. pp:288 $-292$.

[6] Nagasaka, K. and Al Mamun, M. (2004). Long-term peak demand prediction of 9 Japanese power utilities using radial basis function networks. Power Engineering Society General Meeting, IEEE, 1: 315-322.

[7] Ganjavi, M.R. (2001). Coordinated comprehensive design of distribution systems at medium and low voltage levels, 16th. International Conference and Exhibition on Electricity Distribution (CIRED 2001), Amsterdam, Netherlands.

[8] Lu, F.C. and Hsu, Y.Y. (1995). Reactive power/voltage control in a distribution substation using dynamic programming, IEE Proceedings, Generation, Transmission and Distribution, 142, Issue (6): 639-645.

[9] Yn, Y., Wang, C., Ge, S., Xiao, J., Yan, X. and Huang, C. (2000). Models and Methods for Urban Distribution Planning, School of Electrical and Automation Engineering, Tianjin University, Perth, WA, Australia.

[10] Saudi Electricity Company. (2010). Annual Reports for the year 2010 and the previous years, West Region Branch: Jeddah Head Quarter.

[11] Chamber of Commerce and Industry in Jeddah (2010). Official Reports.

[12] Hanke, J.E. and Wichern, D.W. (2008). Business Forecasting. Ninth Edition. Printice-Hall, Inc. 
[13] Neuro Dimension Inc. (2008). NeuroSolution Getting Started Manual Version 5, from: www.nd.com.

[14] Evans, M.K. (2005), Practical Business Forecasting, Blackwell Publishers, Oxford.

[15] Carnot, N., Koen, V. and Tissot, B. (2005), Economic Forecasting, Palgrave/MacMillan.

[16] Hillier F.S. and Lieberman G.J. (2005). Introduction to Operations Research, Eighth Edition, McGraw-Hill Companies, Inc., New York.

[17] Walkenbach, J.E. (2007). Power Programming with VBA, Wiley Publishing, Inc.

[18] Jelen, B. and Syrstad, T. (2008). VBA and Macros for Microsoft Office Excel 2007, Que. 


\section{الجدولة الاقتصادية لمحطات النقل والتوزيع الكهربائية في مدينة جدة مع نتائج بارامتريـة}

\section{سعيد علي القليطي، و محمد رضا كابلي}

قسم الهندسة الصناعية، جامعة الملك عبدالعزيز، جدة، المدلكة العربية السعودية

السستخلص. تركز هذه الورقة العلمية على الجدولة الاقتصادية لعدد

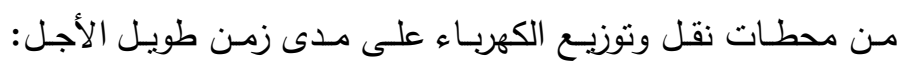

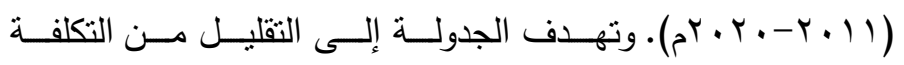

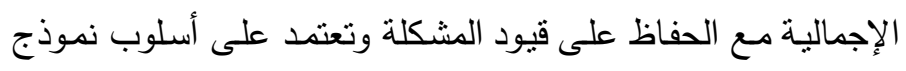

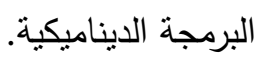

وهناك الكثير من العوامل التي تؤثر في حل المشكلة، وهذه

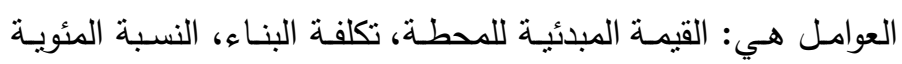

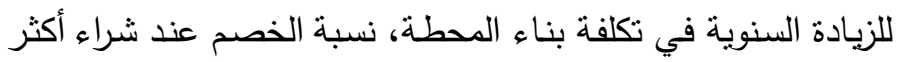
من محطة واحدة، وقيم تكاليف التشغيل الحالية والمستقلية.

وسوف يقدم نموذج البرمجة الديناميكية الدقترح للثركة

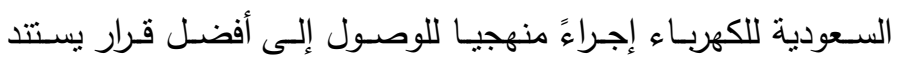

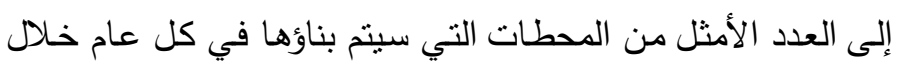

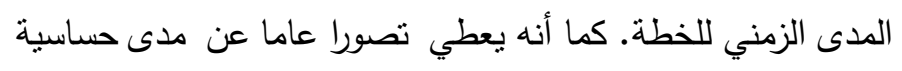

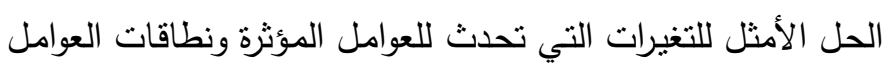

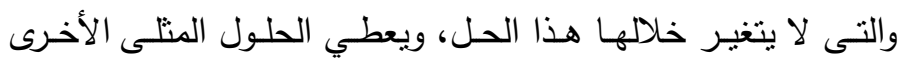
عندما تتخير تلاكل العوامل خارج هذه النطاقات. 